\title{
DIAGNOSTICS OF HF RADIO CHANNEL: BASED ON DATA FROM BACKSCATTER IONOSPHERIC SOUNDING BY CONTINUOUS CHIRP SIGNAL
}

\section{S.N. Ponomarchuk}

Institute of Solar-Terrestrial Physics SB RAS, Irkutsk,Russia,spon@iszf.irk.ru

\author{
V.P. Grozov \\ Institute of Solar-Terrestrial Physics SB RAS, \\ Irkutsk,Russia,grozov@iszf.irk.ru
}

G.V. Kotovich

Institute of Solar-Terrestrial Physics SB RAS, Irkutsk,Russia,kotovich@iszf.irk.ru

\author{
V.I. Kurkin \\ Institute of Solar-Terrestrial Physics SB RAS, \\ Irkutsk, Russia, kurkin@iszf.irk.ru \\ M.S. Penzin \\ Institute of Solar-Terrestrial Physics SB RAS, \\ Irkutsk, Russia,penzin@iszf.irk.ru
}

\begin{abstract}
Backscatter ionospheric sounding (BIS) is a powerful tool for monitoring and predicting conditions of operation of HF communication systems. The BIS method is adopted to determine coverage areas of radio waves and maximum usable radio frequencies, distance along the ground to a scatterer, as well as to gain information about ionospheric structure and conditions. To solve these problems, we propose a method for direct diagnostics of $\mathrm{HF}$ radio channel at the leading edge of BIS signals on ionograms. The method relies on real-time automatic processing and interpretation of BIS ionograms. We present
\end{abstract}

algorithms for determining the maximum usable frequencies and characteristics of oblique sounding signals from current BIS data, without correcting ionospheric parameters. We realize the algorithm for recovering ionospheric parameters at the path midpoint.

Keywords: ionosphere, ionogram, radio wave propagation, backscatter ionospheric sounding.

\section{INTRODUCTION}

Backscatter ionospheric sounding (BIS) has been widely used for ionospheric research along with vertical (VIS) and oblique (OIS) ionospheric sounding since the 1940s. It has also been utilized to predict operating conditions in radio channels [Benner, 1949; Kabanov, Osetrov, 1965; Chernov 1971]. The BIS signal is affected by the same factors that influence signals of the main radio channels. It is therefore natural to expect that BIS signal parameters and their variations can be used to predict propagation conditions in radio channels. Moreover, the BIS signal contains information about ionospheric conditions at a distance of several thousand kilometers from the observation point in any given direction. This considerably increases the capabilities of VIS stations for studying the ionosphere and predicting its parameters. There are several basic approaches to identifying radio communication characteristics from BIS data. The most common approach relies on the solution of the so-called inverse problems when quantitative ionospheric parameters are determined from BIS data. The measured characteristics generally includes delays of a sounding signal, which correspond to the leading edge of the BIS signal [Benito et al., 2008; Fridman et al., 2012; Norman et al., 2013; Zhu et al., 2015; Feng et al., 2016]. The use of such methods usually requires much time for computer calculations, thereby greatly reducing the applicability of BIS tools for monitoring working conditions in HF radio channels.

One of the possible ways to predict radio commu- nication characteristics in real time is the method for direct radio diagnostics allowing us to determine radio channel characteristics from a sounding signal without correcting ionospheric parameters [Kurkin et al., 1993]. This approach is adopted when the diagnostic OIS path coincides with the radio path of interest or lies within the BIS sector. This paper presents a method for real-time diagnostics of HF radio channel from results of automatic processing and interpretation of BIS ionograms, obtained with a chirp ionosonde developed by ISTP SB RAS [Brynko et al,. 1988; Podlesniy et al., 2013]. The results of interpretation of BIS signals and construction of tracks are the initial data for determining OIS maximum usable frequencies (MUF) and distance-frequency characteristics (DFC) at given distances. Then, the results of real-time diagnostics of HF radio channel from current BIS data are used to recover ionospheric parameters of the sounding sector.

\section{METHOD FOR DIRECT DIAGNOSTICS OF RADIO CHANNEL}

The simulation of OIS and BIS signal characteristics and the analysis of experimental data have revealed the following ratios slightly depending on ionospheric parameter variations [Kurkin et al., 1993; Ponomarchuk et al., 2009, 2012]:

- the ratio of the group path $P_{\mathrm{m}}$, which corresponds to the leading edge of the BIS signal, to the distance to the boundary of an illuminated zone $D_{\mathrm{m}}\left(P_{\mathrm{m}} / D_{\mathrm{m}}\right)$; 
- DFC of the oblique propagation mode at the relative frequency grid $\beta=f / f_{\mathrm{m}}$, where $f_{\mathrm{m}}$ is the MUF mode for the range considered $(P(\beta))$;

- DFC of the BIS signal at the leading edge at the relative frequency grid $v=f / f_{\mathrm{m}}$, where $f_{\mathrm{m}}$ is MUF for a maximum BIS signal range.

These ratios allow the following problems of realtime diagnostics of decameter radio channel to be solved:

- interpretation of propagation modes on experimental BIS ionograms from high-amplitude points resulting from secondary processing;

- reconstruction of BIS ionograms from track fragments when technical capabilities of the ionosonde or conditions along the propagation path do not allow us to obtain the frequency dependence of the group path of a mode;

- real-time determination of MUF and DFC of BIS signals along a given radio path from BIS data.

The position of the boundary of the illuminated zone is found from DFC of BIS signals at the leading edge because the maximum in the amplitude relief of the BIS signal in the group path is close to the boundary of the leading edge [Dyson, 1991; Ponomarchuk et al., 2009]. BIS ionograms can therefore be interpreted by calculating the frequency dependence of the minimum group path $P_{\mathrm{m}}(f)$ corresponding to the closing point of upper and lower rays for BIS signals [Ponomarchuk et al., 2016]. The operating frequency $f$ for the corresponding distance $D_{\mathrm{m}}(f)$ is the maximum usable radio frequency. Characteristics of BIS and OIS signals are simulated using the waveguide approach with the IRI model [Ilyin et al., 1996; Bilitza, Reinisch, 2008; Ponomarchuk et al., 2009; Ponomarchuk et al., 2014].

\section{DATA PROCESSING AND INTERPRETATION}

A determining factor in the real-time prediction of radio channel characteristics is the automation of secondary processing and analysis of processing diagnostic information about HF radio channel conditions. Ionogram processing includes the following stages [Grozov et al., 2012; Ponomarchuk et al., 2012; Grozov et al., 2013]:

a) ionogram preprocessing in order to remove noise from an image and improve amplitude characteristics;

b) data compression allowing a significant reduction in their volume without appreciable loss of useful information.

Ionogram preprocessing involves removing noise components from an ionogram to isolate a useful signal, as well as removing single outliers comparable in intensity with the useful signal. Noise is eliminated using local smoothing techniques, which have high computational efficiency and can process images in real time. To remove noise from an image and to recover signal samples, we employ a median filter capable of smoothing noises and reducing blurring of track boundaries, as well as restoring values in track breaks. When switching between realizations at adjacent frequencies, the low correlation of noises causes the noise to become impulsive; it is best removed by the median filter.
A data compression technique is used to select highamplitude points corresponding physically to the moments of signal arrival at the leading edge of the signal or to the amplitude relief maximum. To exclude individual artifacts, partially recover data, and detect the primary track on ionograms, the cellular automaton mechanism can be effectively utilized. Cellular automata are discrete dynamic systems whose behavior is completely determined by local interconnections between elements of these systems. This processing leaves points on ridges of the tracks and slight noise. The implemented algorithm allows us to compress the source information 5-10 times depending on noise and diffusion levels.

Figure 1 shows a BIS ionogram (a) and secondary processing results $(b)$. The transmission point is Usolye Sibirskoe $\left(52.88^{\circ} \mathrm{N}, 103.26^{\circ} \mathrm{E}\right)$. The reception point is Tory $\left(51.8^{\circ} \mathrm{N}, 103.0^{\circ} \mathrm{E}\right)$. The transmission azimuth is $55^{\circ}$. The time of recording is 08:40 UT on September 25,2005 . The chirp ionosonde in hand has a transmitter power of less than $1 \mathrm{~kW}$; it therefore can record scattered signals within the maximum range of one hop $(\sim 3000 \div 4000 \mathrm{~km})$ in the BIS mode. The isolated scattered BIS signals on the ionogram in Figure 1 correspond to a single reflection from the F2 layer.

The BIS DFC recovery algorithm is based on the adiabatic dependence of the minimum group path of a signal scattered by the Earth surface at the relative frequency grid $v=\mathrm{f} / \mathrm{fm}$ under variations in ionospheric

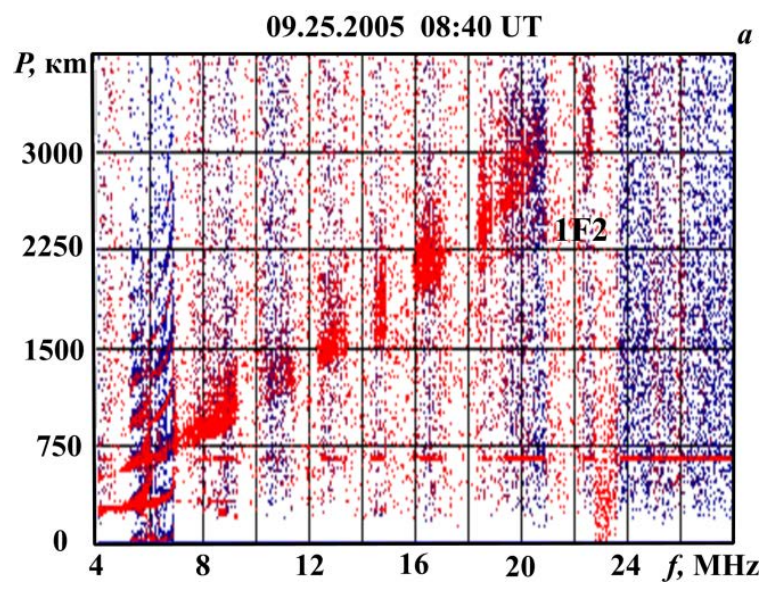

09.25.2005 08:40 UT b

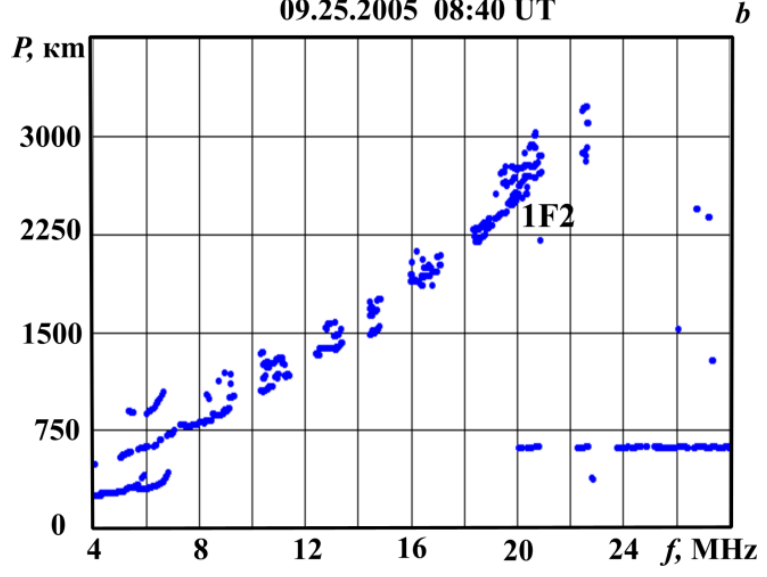

Figure 1. BIS ionogram (a) and secondary processing results (b) $(09.25 .2005,08: 40 \mathrm{UT})$ 
parameters. For predictive ionospheric parameters at the frequency grid, we compute DFC of BIS signals at the leading edge. Characteristics of BIS signals at the leading edge are simulated using the waveguide approach with the IRI model [Bilitza, Reinisch, 2008; Ponomarchuk et al., 2009]. The predictive DFC of the BIS signal is recalculated to the relative frequency grid $v$. As the frequency $f_{\mathrm{m}}$ we take MUF for a maximum signal range. The secondary processing of the experimental BIS ionogram yields a matrix of experimental points, which corresponds to a two-dimensional array of the group path $P_{i}$ at the frequency grid $f_{j}$ for the high-amplitude points. Experimental points are also converted into the grid frequency $v$. The algorithm for automatic identification of the propagation mode on a BIS ionogram involves determining the maximum of distribution of the number of experimental points in a model mask, constructed based on the long-term prediction, for changing frequency $f_{\mathrm{m}}$ at the relative frequency grid $v=f / f_{\mathrm{m}}$.

Figure 2 presents the results of secondary processing and interpretation of a BIS ionogram. Lines 1 and 2 show the results of the simulation of $P_{\mathrm{m}}$ and $D_{\mathrm{m}}$ from a long-term prediction; line 3 is the interpreted BIS DFC; black dots are high-amplitude points of the BIS signal.

\section{REAL-TIME DIAGNOSTICS}

The methods developed for automatic processing and interpreting BIS ionograms enable us to solve the following problems of real-time diagnostics of the decameter radio channel from current BIS ionograms:

- real-time determination of MUF and DFC of OIS signals for the $1 \mathrm{~F} 2$ propagation mode along a given radio path from BIS data;

- reconstruction of spatial electron density distribution in the zone of backscatter ionospheric sounding with a chirp ionosonde.

MUF of the OIS signal at the given radio path length for current DFC of BIS signals is calculated from the adiabatic ratio $\mathrm{Pm} / \mathrm{Dm}$. At the first stage, for the estimated ionospheric parameters, we compute the distance-

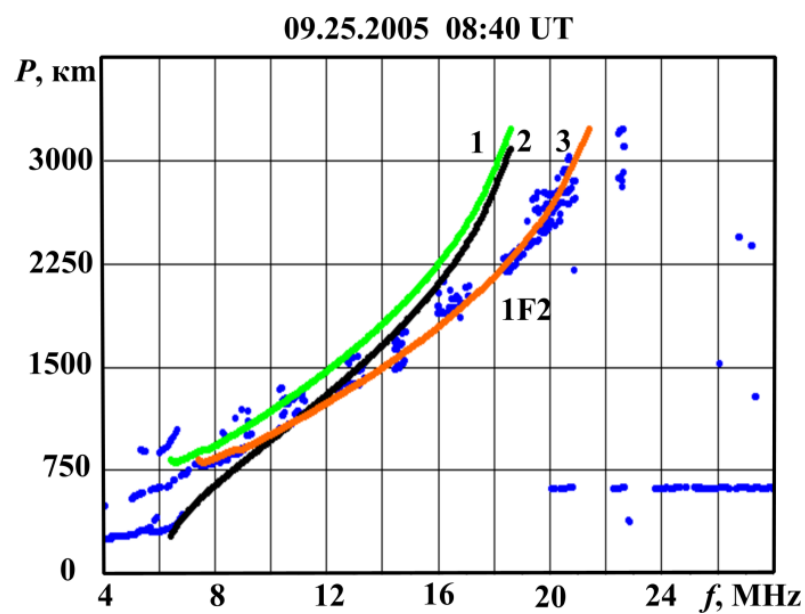

Figure 2. Results of secondary processing and interpretation of the BIS ionogram obtained on September 25, 2005, at 08:40 UT: Line 1 is $P_{\mathrm{m}}$; line 2 is $D_{\mathrm{m}}$; line 3 is BIS DFC; black dots are high-amplitude points of the BIS signal frequency characteristics of $P_{\mathrm{m}}(f)$ and $D_{\mathrm{m}}(f)$. For a given distance $D_{0}$, we calculate the ratio $\eta=P_{\mathrm{m}} / D_{0}$. Then, for the real BIS DFC at the leading edge of the signal, we determine the frequency for which the group path is equal to $P=\eta D_{0}$. The frequency thus estimated is the actual frequency $f_{\mathrm{m}}$ for $D_{0}$. After determining MUF for a given range from current BIS data, we can calculate actual OIS DFC for the corresponding propagation mode. DFC of OIS for $D_{0}$ is calculated from the longterm prediction of ionospheric parameters at the relative frequency grid $\beta=f / f_{\mathrm{m}}^{\text {predict }}$. The actual OIS DFC at the current time is restored from the predicted one by multiplying $\beta$ by $f_{\mathrm{m}}$ [Kurkin et al., 1993; Grozov et al., 2012].

Figure 3 shows the results of the recalculation of estimated OIS DFC of the 1F2 mode to actual signal delays at the distance grid from MUF, restored from the current BIS DFC presented in Figure 2. The time of recording is 08:40 UT on September 25, 2005. The geometry of the sounding sector in this experiment is depicted in Figure 4 . The central azimuth of $55^{\circ}$ coincides with the direction to Magadan.

To illustrate capabilities of the method for correcting MUF from BIS data, Figure 5 presents the results of the comparison of OIS DFC for the 1F2 one-hop mode at a distance of $3000 \mathrm{~km}$ from the transmitter with an experimental OIS ionogram obtained over the Magadan-Tory path (the path length is $\sim 3000 \mathrm{~km}$ ) at 08:45 UT. The dashed line indicates the results of the OIS DFC simulation within the waveguide approach using IRI; the solid line is the results of the reconstruction.

Figure 6 shows time variations in MUF of the $1 \mathrm{~F} 2$ one-hop mode for $3000 \mathrm{~km}$ toward Magadan for November 18 and 19, 2005. To correct MUF for this distance, we used data obtained from automatic processing and interpretation of BIS ionograms [Ponomarchuk et al., 2016]. The solid line indicates MUF calculated from the results of the reconstruction of OIS DFC from current BIS data. The dashed line shows

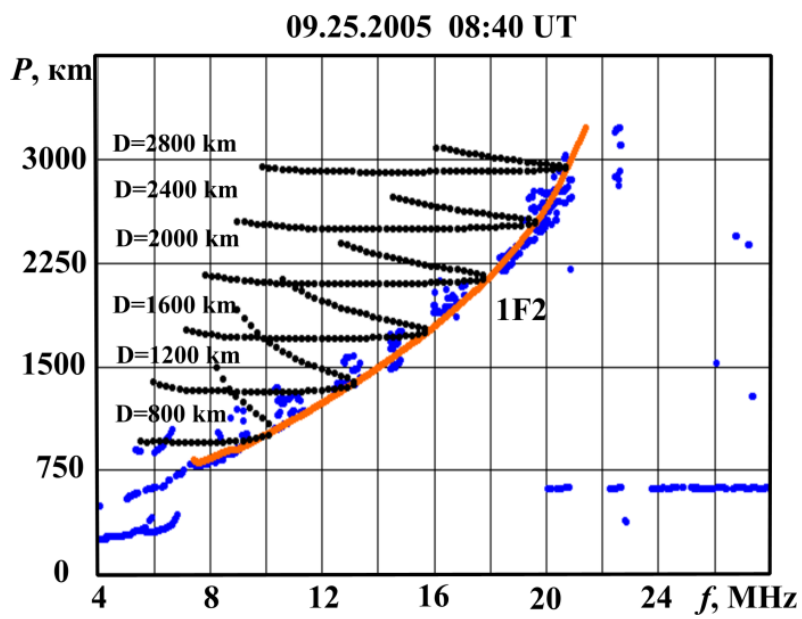

Figure 3. Results of the secondary processing, interpretation of BIS ionograms (09.25.2005, 08:40 UT), and OIS DFC at the distance grid 


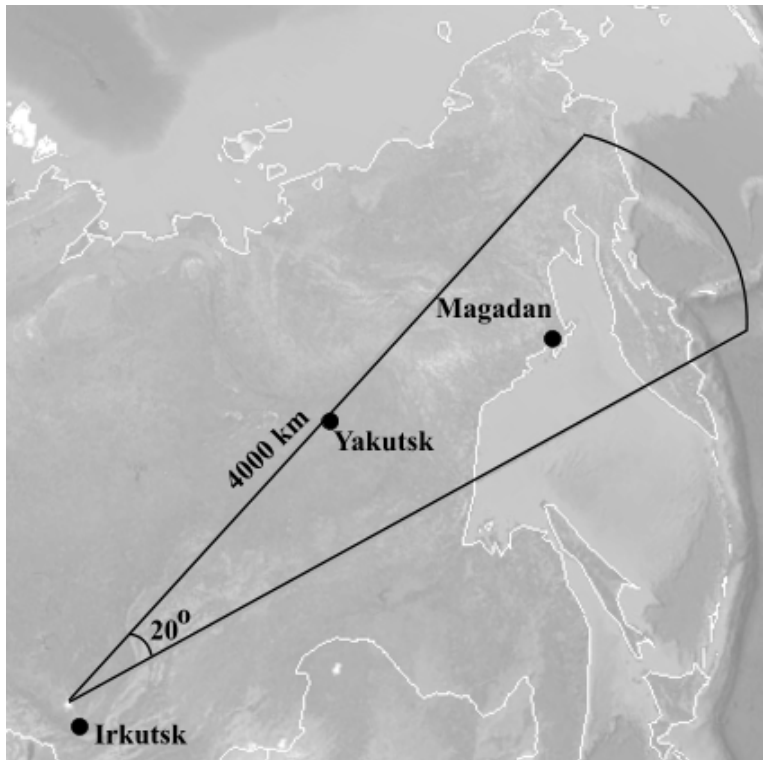

Figure 4. Sounding sector with the central azimuth of $55^{\circ}$

09.25.2005 08:45 UT

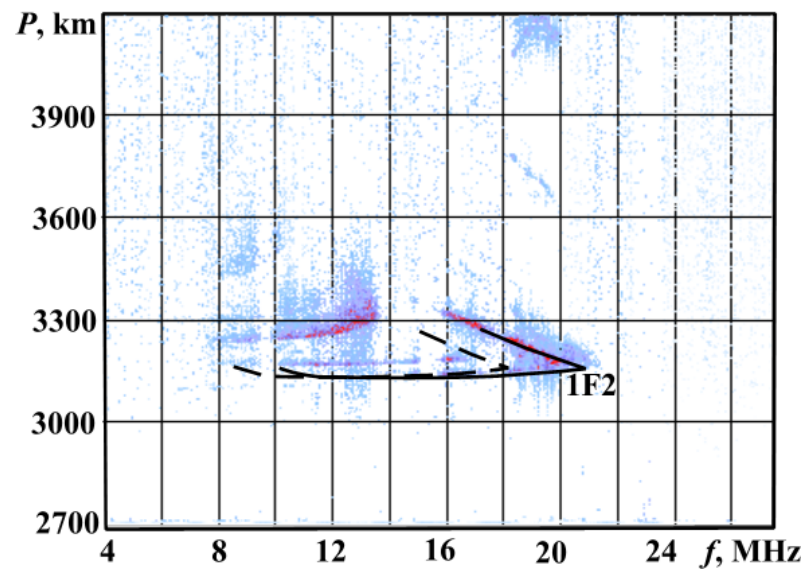

Figure 5. OIS ionogram (09.25.2005, 08:45 UT) and OIS DFC obtained for 08:40 UT on the same day: from IRI (dashed line), from reconstruction (solid line)

the experimental values of maximum observed frequencies (MOF) over the Magadan-Tory path during this period of observations.

The 1-2 hr variations in $\sim 2 \mathrm{MHz}$ MOF are caused by traveling ionospheric disturbances (TID) along the path [Ivanova et al., 2011]. MUF calculated from current BIS data are consistent with the experimental MOF (Figure 6). To correct MUF with respect to traveling ionospheric disturbances, as input data on the BIS ionogram we should select a flock of highamplitude points corresponding to moments of arrival of scattered signals from different directions. This problem can be solved using SuperDARN data. Characteristics of the BIS signal received by a SuperDARN radar are employed to diagnose medium- and largescale TID [Oinats et al., 2016].

Thus, the advanced methods for direct diagnostics of radio channel from BIS data allow real-time correction of MUF and DFC of OIS signals over a given path from current BIS data in a sounding sector, without reconstructing ionospheric parameters.
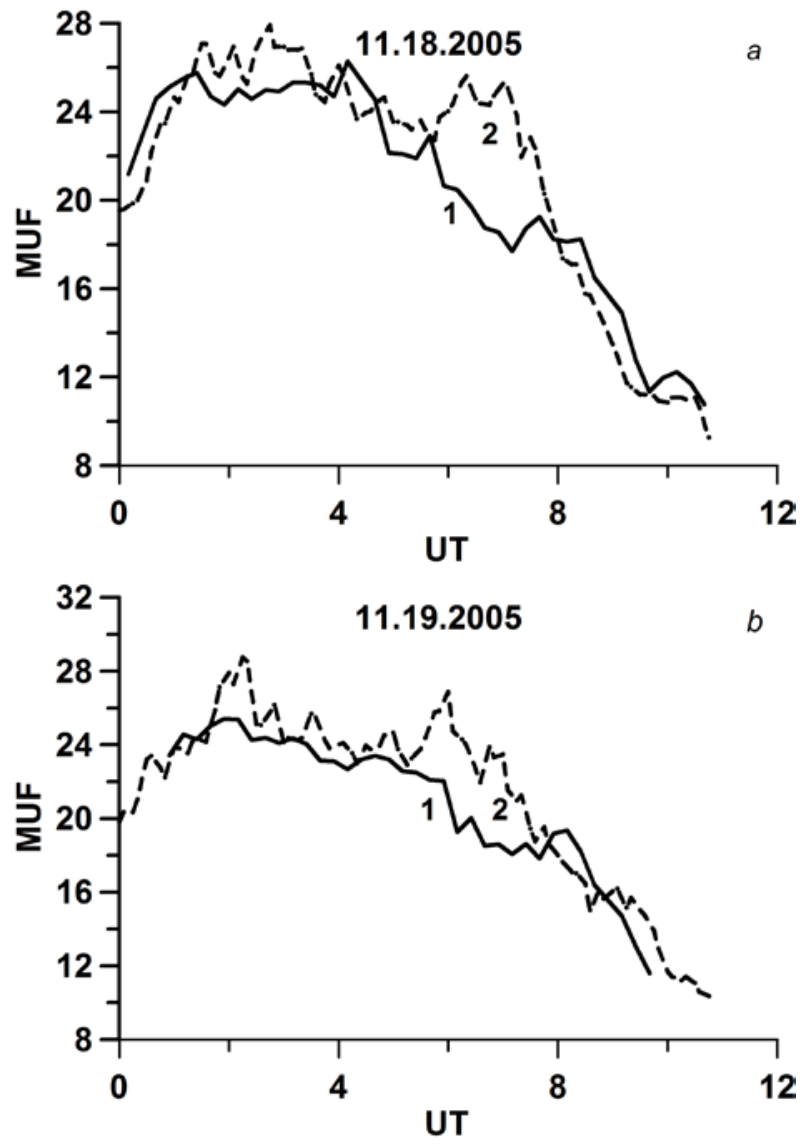

Figure 6. Time variations of real and reconstructed MUF over the Magadan-Tory path: reconstructed MUF (line 1), actual MOF (line 2)

The results of real-time diagnostics of radio channel from BIS data - BIS DFC at the leading edge $P_{\mathrm{m}}(f)$, reconstructed OIS DFC and MUF for a given radio path - can also be utilized as input parameters for solving the inverse problem of determining ionospheric parameters from sounding data. The inverse problem of determining ionospheric parameters from OIS DFC has been addressed by many authors. Smith [1970] suggested solving this problem by reducing a system of integral equations to a system of nonlinear equations through a piecewise hyperbolic approximation of the monotonic vertical electron density profile. Krasheninnikov and Liannoy [1990] used a quasiparabolic piecewise approximation of squared plasma frequency to improve the accuracy of reconstruction of the electron density profile. For real-time calculation of ionospheric parameters, Kotovich et al. [2006] proposed a technique of inversion of OIS DFC to height-frequency characteristic (HFC) of vertical ionospheric sounding near the path midpoint with the modified Smith method (transmission curve method). This technique was adopted to realize the algorithm of HFC calculation at path midpoints located in the BIS sector, with subsequent reconstruction of the electron density profile [Mikhailov, 2000].

In the modified transmission curve method, the linear relationship between VIS $f_{\mathrm{o}}$ and OIS $f_{\mathrm{H}}$ frequencies is given by $f_{\mathrm{H}}=k f_{\mathrm{o}} \sec \varphi$, where $\varphi$ is the angle of incidence of a ray on a layer, $k$ is the Smith 
coefficient reflecting spherical Earth. In this method, the angle of incidence $\varphi$ of a ray on a layer, according to the equivalence theorem, is related to the current height $h$ ' by the following formula:

$$
\varphi=\operatorname{arctg}\left(\frac{\sin (D / 2 R)}{x-\cos (D / 2 R)}\right),
$$

where $x=\frac{R+h^{\prime}}{R}, R$ is the Earth radius. The group decameter signal path $P$ at oblique propagation is determined as follows:

$$
P=2 R \frac{\sin (\Omega-\varphi)}{\sin \varphi},
$$

where $\Omega$ is $\arcsin (x \sin \varphi)$. The OIS ionogram represents the group propagation time as a function of sounding frequency. In each frequency $f_{\mathrm{H}}$, the group propagation time depends on the height of reflection. To find the desired $h^{\prime}$ corresponding to the signal delay at $f_{\mathrm{H}}$ on the OIS ionogram during one-hop propagation (1F2 mode), the operating heights, used to calculate the group propagation time, are selected with a step of $200 \mathrm{~m}$, starting from $200 \mathrm{~km}$. This yields a value of the group path equal to the experimental value at a selected frequency. According to the secant law, the OIS frequency $f_{\mathrm{H}}$ is employed to calculate the VIS frequency $f_{\mathrm{o}}$. Thus, VIS HFC is calculated at the path midpoint. To reconstruct the vertical plasma frequency profile $f_{\mathrm{e}}(h)$, a method has been developed for numerical solution of integral equations by the modified Jackson method with increasing accuracy in regions of layer maxima (near-critical frequencies) and valleys [Mikhailov, 2000].

The obtained $f_{\mathrm{e}}(h)$ profile is used to determine the F2layer parameters, namely the critical frequency $f_{\mathrm{o}} \mathrm{F} 2$ and the height of maximum electron density $h_{\mathrm{m}} \mathrm{F} 2$. Accuracy characteristics of the method of calculating ionospheric parameters near the path midpoint from current OIS data are discussed in [Ponomarchuk et al., 2015].

Figure 7 exemplifies the plasma frequency profiles $f_{\mathrm{e}}(h)$ obtained at a distance of $1500 \mathrm{~km}$ from the transmission point in a sounding direction of $55^{\circ}$. The solid line shows the $f_{\mathrm{e}}(h)$ profile derived from VIS data from Yakutsk $\left(62^{\circ} \mathrm{N}, 129.7^{\circ} \mathrm{E}\right)$ for November 19, 2005 02:15 UT; dashed line is the $f_{\mathrm{e}}(h)$ profile calculated by IRI [Bilitza, Reinisch, 2008]; dots are the results of the

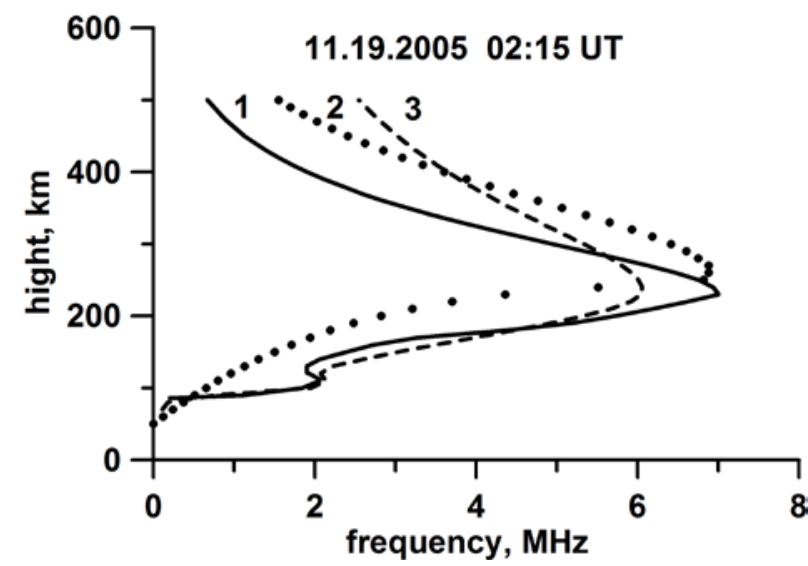

Figure 7. Plasma frequency profiles $f_{\mathrm{e}}(h): 1-$ actual, $2-$ reconstructed, 3 - from IRI calculation of $f_{\mathrm{e}}(h)$ from VIS HFC, reconstructed from OIS DFC for $3000 \mathrm{~km}$. OIS DFC was calculated from current BIS data during the given period. The difference in latitude of the VIS station and the average path midpoint $\left(58.2^{\circ} \mathrm{N}, 124.2^{\circ} \mathrm{E}\right)$ is $\sim 4^{\circ}$, and the distance between the points is approximately equal to $500 \mathrm{~km}$; the Yakutsk data can therefore only partially represent control data in verification of methods for diagnostics of ionospheric parameters.

To illustrate the method for diagnostics of ionospheric parameters from BIS data, Figure 8 presents the results of the determination of the F2-layer critical frequency at the Magadan-Tory path midpoint from OIS DFC, recovered from the current BIS data obtained on November 18 and 19, 2005 (see Figure 6). The solid line in Figure 8 shows critical frequency variations as derived from data acquired by the VIS station located in Yakutsk. The $\sim 1 \mathrm{hr}$ variations in $\sim 1 \mathrm{MHz} f_{\mathrm{o}} \mathrm{F} 2$ are caused by the presence of traveling ionospheric disturbances over Yakutsk during this period [Kurkin et al., 2014]. Values of the F2-layer critical frequency, calculated from OIS DFC recovered from BIS data, are consistent with experimental data.

Note that the analytical expressions for $P_{\mathrm{m}}$ and $D_{\mathrm{m}}$, obtained in the spherically symmetric waveguide with the model quasiparabolic electron density profile, allow us to determine the critical frequency and F2-layer maximum height from current BIS data at the leading edge of the signal [Li et al., 2013].
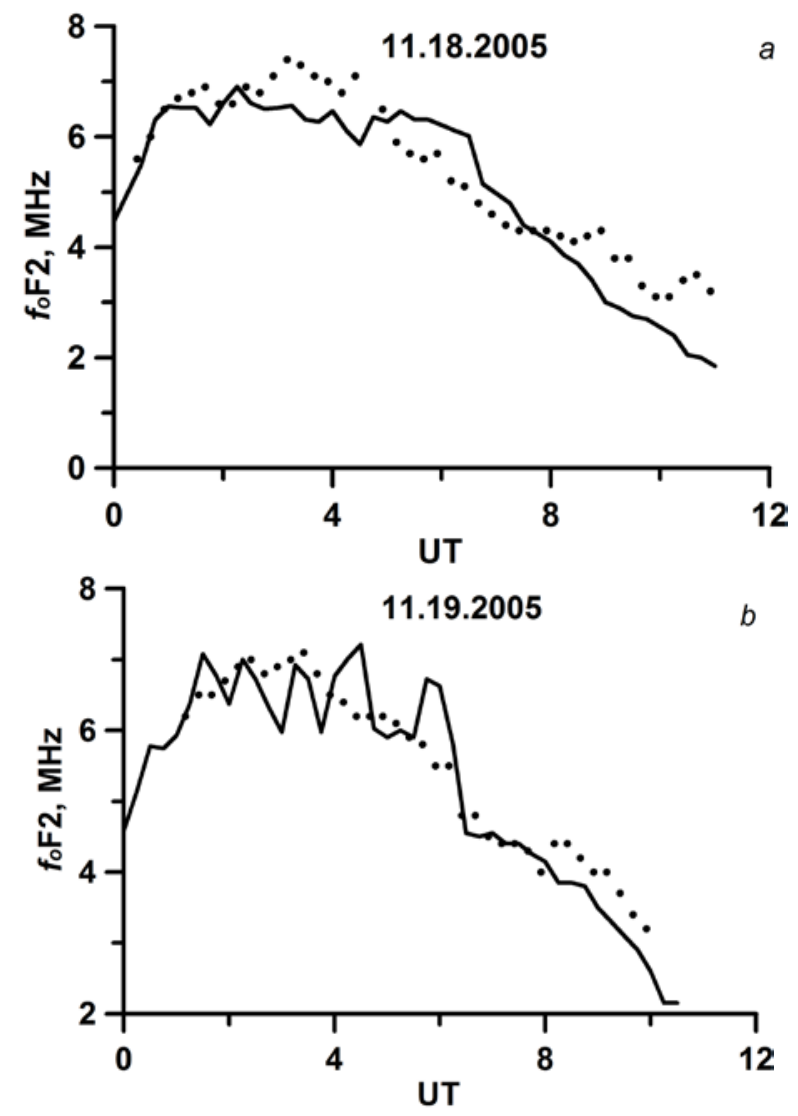

Figure 8. Time variations in the F2-layer critical frequency at the Magadan-Tory path midpoint: experimental $f_{0} \mathrm{~F} 2$ at the station Yakutsk (solid line); recovered $f_{0} \mathrm{~F} 2$ at the path midpoint (dots) 


\section{CONCLUSION}

We have presented a method for real-time diagnostics of HF radio channel from results of automatic processing and interpretation of BIS ionograms obtained with a chirped ionosonde. We use slightly varying ratios of frequency dependences of group characteristics of OIS and BIS signals. Signals on an ionogram are interpreted from the calculation of the BIS distancefrequency characteristic at the leading edge of the signal. Radio wave propagation characteristics are simulated using the waveguide approach with the IRI model. The results of identification of recorded BIS signals and construction of paths are the initial data for determining MUF and DFC of the 1F2 one-hop mode of oblique propagation along radio paths and in the sounding sector, without correcting ionospheric parameters. For realtime reconstruction of ionospheric parameters, we employ an algorithm based on inversion of OIS DFC to VIS HFC nearby the path midpoint, with subsequent reconstruction of the electron density profile, thus solving the inverse VIS problem. In the future, we plan to carry out further studies of the quantitative evaluation of effectiveness of the method for diagnostics of decameter radio channel from current BIS data, using an automated software package of ionogram processing and interpretation.

The work was carried out with budgetary funding of Basic Research program II.12. The results were obtained using the equipment of Center for Common Use “Angara” http://ckp-rf.ru/ckp/3056.

\section{REFERENCES}

Benito E., Bourdillon A., Saillant S., Rannou V., Molinié J.P. Inversion of HF backscatter ionograms using elevation scans. J. Atmos. Terr. Phys. 2008, vol. 70, no. 15, pp. 1935-1948. DOI: 10.1016/j.jastp.2008.09.031.

Benner A.H. Predicting maximum usable frequency from long-distance scatter. Proc. IRE. 1949, vol. 37, no. 1, pp. 4447.

Bilitza D., Reinisch B.W. International Reference Ionosphere 2007: Improvements and new parameters. Adv. Space Res. 2008, vol. 42, pp. 599-609. DOI: 10.1016/j.asr.2007.07.048.

Brynko I.G., Galkin I.A., Grozov V.P., Dvinskikh N.I., Matyushonok S.M., Nosov V.E. An automatically controlled data gathering and processing system using an FMCW ionosonde. Adv. Space Res. 1988, vol. 8, no. 4, pp. 121-124.

Chernov Yu.A. Vozvratno-naklonnoe zondirovanie ionosfery [Backscatter Sounding Ionosphere]. Moscow, Sov. svyaz’ Publ., 1971, 204 p. (In Russian).

Dyson P.L. A simple method of backscatter ionogram analysis. J. Atmos. Terr. Phys. 1991, vol. 53, no. 1, pp. 75-88.

Fridman S.V., Nickisch L.J., Hausman M. Inversion of backscatter ionograms and TEC data for over-the-horizon radar. Radio Sci. 2012, vol. 47, RS0L10. DOI: 10.1029/2011RS004932.

Grozov V.P., Ilyin N.V., Kotovich G.V., Ponomarchuk S.N. Software system for automatic interpretation of ionosphere sounding data. Pattern Recognition and Image Analysis. 2012, vol. 22, no. 3, pp. 458-463. DOI: 10.1134/S1054661812030042.

Grozov V.P., Kiselev A.M., Kotovich G.V., Mikhailov S.Ya., Ponomarchuk S.N. The software for processing and interpretation of sounding ionogram on base of digital chirp sounder. Geliogeofizicheskie issledovaniya [Heliogeophysical Research].
2013, vol. 4, pp. 75-85. (In Russian).

Ilyin N.V., Khakhinov V.V., Kurkin V.I., Nosov V.V., Orlov I.I., Ponomarchuk S.N. The theory of chirp-signal ionospheric sounding. Proc. ISAP'96. Chiba, Japan, 1996, pp. 689-692.

Ivanova V.A., Kurkin V.I., Polekh N.M., Chistyakova L.V., Brynko I.G., Chuyev V.V., Dumbrava Z.F., Poddelskii I.N. Studying large-scale traveling ionospheric disturbances according to the data of oblique-incidence sounding. Geomagnetism and Aeronomy. 2011, vol. 51, no. 8, pp. 1101-1104.

Feng J., Ni B.-B., Zhao Z.-Y., Liu W., Wei N., Lou P. A method of reconstructing horizontally-inhomogeneous ionospheric structure using HF sky-wave backscatter ionograms. Chinese J. Geophys. 2016, vol. 59, no. 5, pp. 457-473.

Kabanov N.I., Osetrov B.I. Vozvratno-naklonnoe zondirovanie ionosfery [Backscatter Sounding Ionosphere]. Moscow, Svyaz’ Publ., 1965, 112 p.

Kotovich G.V., Kim A.G., Mikhailov S.Ya., Grozov V.P., Mikhailov Ya.S. Determining the foF2 critical frequency at the path midpoint from oblique sounding data based on the Smith method. Geomagnetism and Aeronomy. 2006, vol. 46, no. 4, pp. 517-521. DOI: 10.1134/S0016793206040141.

Krasheninnikov I.V., Liannoy B.E. Estimation of the true ionospheric height profile, with a continuous gradient, from oblique sounding data. J. Atmos. Terr. Phys. 1990, vol. 52, no. 2, pp. 113-117.

Kurkin V.I., Laryunin O.A., Podlesny A.V., Pezhemskaya M.D., Chistyakova L.V. Studying morphological characteristics of traveling ionospheric disturbances with the use of near-vertical ionospheric sounding data. Atmospheric and Oceanic Optics. 2014, vol. 27, iss. 4. pp. 303-309. DOI: 10.1134/ S1024856014040095.

Kurkin V.I., Nosov V.E., Ponomarchuk S.N., Savkov S.S., Chistyakova L.V. Method for operative diagnostics of HF radio channel. Issledovaniya po geomagnetizmu, aeronomii $i$ fizike Solntsa [Research on Geomagnetism, Aeronomy and Solar Physics]. Novosibirsk, Nauka Publ., 1993, vol. 100, pp. 168-188. (In Russian).

Li N., Zhao Z., Zhou C., Chen G., Yang G., Huang S., Li T. Inversion of sweep frequency backscatter ionogram from monostatic HF sky-wave radar. IEEE Geoscience and Remote Sensing Letters. 2013, vol. 10, no. 6, pp. 1360-1364. DOI: 10.1109/LGRS.2013.2241728.

Mikhailov S.Ya. Ambiguity of the reconstruction of plasma frequency profiles from a given height-frequency chara teristic and their discernibility for oblique propagation of $\mathrm{H}$ radio waves in an isotropic ionosphere. Radiophysics ana Quantum Electronics. 2000, vol. 43, no. 10, pp. 766-782.

Norman R.J., Dyson P.L. HF radar backscatter inversion technique. Radio Sci. 2006, vol. 41, RS4010. DOI: 10.1029/ 2005 S003355.

Oinats A.V., Nishitani N., Ponomarenko P., Ratovsky K.G. Diurnal and seasonal behavior of the Hokkaido East SuperDARN ground backscatter: simulation and observation. Earth, Planets and Space. 2016, vol. 68, no. 1, pp. 18. DOI: 10.1186/ s40623015-0378-9.

Podlesnyi A.V., Brynko I.G., Kurkin V.I., Berezovsky V.A., Kiselev A.M., Petukhov E.V. Multifunctional chirp ionosonde for monitoring the ionosphere. Geliogeofizicheskie issledovaniya [Heliogeophysical Research]. 2013, no. 4, pp. 24-31. (In Russian).

Ponomarchuk S.N, Kurkin V.I., Oinats A.V. The Diagnostics of ionosphere and Earth ground surface by backscatter sounding data. Proc. PIERS 2009. Moscow, 2009, vol. I, II, pp. 1307-1310.

Ponomarchuk S.N., Grozov V.P., Kotovich G.V., Penzin M.S. The real-time forecast of HF radio channel on the base of ionosphere sounding data. Proc. PIERS 2012. Mos- 
cow, 2012, pp. 1182-1186.

Ponomarchuk S.N., Grozov V.P., Kim A.G., Kotovich G.V., Podlesniy A.V. The near real-time diagnostics of ionosphere parameters at the middle point of the radio path on the base of oblique sounding data. Proc. SPIE. 2015, vol. 9680, 96805E. DOI: $10.1117 / 12.2203589$.

Ponomarchuk S.N., Grozov V.P., Kotovich G.V., Kurkin V.I., Penzin M.S. Automatic processing and interpretation of backscatter ionosphere sounding ionograms. Proc. SPIE. 2016, vol. 10035, 100351E. DOI: 10.1117/12.2248765.

Ponomarchuk S.N., Ilyin N.V., Penzin M.S. The model of radio wave propagation in $1-10 \mathrm{MHz}$ frequency range on the base of normal wave technique. Solnechno-zemnaya fizika [Solar-Terr. Phys.]. 2014, iss. 25, pp. 33-39. (In Russian). data given on oblique incidence ionograms. J. Atmos. Terr. Phys. 1970, vol. 32, no. 6, pp. 1047-1056.

Zhu P., Zhou C., Zhang Yu., Yang G., Jiang C., Sun H., Cui $\mathrm{X}$. F region electron density profile inversion from backscatter ionogram based on international reference ionosphere. J. Atmos. Solar-Terr. Phys. 2015, vol. 129, pp. 111118. DOI: 10.1016/j.jastp.2015.05.003.

How to cite this article

Ponomarchuk S.N., Grozov V.P., Kotovich G.V., Kurkin V.I., Penzin M.S. Diagnosis of HF radio channel: based on data from backscatter ionospheric sounding by continuous chirp signal. SolarTerrestrial Physics 2018. vol. 4, iss. 2. pp. 17-23. DOI: 10.12737/stp42201804. 